\title{
Site of Separation of Musculocutaneous Nerve from Axillary Brachial Plexus: Analysis using Ultrasound- Observational Volunteer Study
}

\author{
Balasubramanian Anusha ${ }^{1}$, G. Jayaraman ${ }^{2 *}$ and S. Parthasarathy ${ }^{1}$ \\ 'Department of Anaesthesiology and Critical care, Mahatma Gandhi Medical College and Research Institute, \\ Pillayarkuppam - 607402, Puducherry, India \\ 2Department of Radiodiagnosis, Mahatma Gandhi Medical College and Research Institute, \\ Pillayarkuppam -607402, Puducherry, India; gjayaraman50@gmail.com
}

\begin{abstract}
The axillary approach to brachial plexus blockade provides satisfactory anesthesia for elbow, forearm, and hand surgeries. The use of ultrasound enhances the success of such blocks. The major issue in such a block is the anatomical variation of the musculocutaneous nerve and its possible sparing. The unblocked lateral superficial tissues of forearm and the problem of tourniquet pain will come up if it's spared. Hence in our study we wanted to locate the site of separation of the nerve. In eighty young healthy male volunteers, the scan of the right axillary area showed that the separation was proximal (point C) in 34\% of cases to the classical described site (point A) of combined visualisation of conjoint tendon and axillary artery. It was found separating distally (point B) in $59 \%$ of cases. The distance was maximal in the proximal group with $44 \mathrm{~mm}$ and in the distal group of $35 \mathrm{~mm}$. It was absent in one individual. With such a large variation in anatomy, it is necessary to identify the musculocutaneous nerve separately and block it for a successful anesthetic journey in axillary approach to blocking brachial plexus.
\end{abstract}

Keywords: Anatomy, Axillary, Brachial Plexus, Musculocutaneous Nerve

\section{Introduction}

Axillary approach to brachial plexus blocks (AXB) is being widely used as an anaesthetic method for upper limb operations ${ }^{1}$. It is recommended that AXB should be performed using a multiple injection technique. The important problem with AXB is sparing of musculocutaneous nerve ${ }^{2}$. This nerve supplies the lateral forearm and is being implicated as the reason for tourniquet pain. Hence the blocking of this nerve becomes essential. At terminal nerve level, the Musculocutaneous Nerve $(\mathrm{MCN})$ is usually positioned outside the axillary sheath ${ }^{3}$.
It is believed that it separates early and needs a separate needle prick to block. In this study, we tried is to find the distance at which the musculocutaneous nerve separates from the brachial plexus with respect to classical site of ultrasound approach of AXB.

\section{The Aims of the Study}

- To measure the distance between optimal image for axillary block to a point at which musculocutaneous nerve leaves the axillary sheath and pierces the coracobrachialis muscle. 
- To find out the site of separation and find out the incidence of either proximal or distal separation.

\section{Material and Methods}

Eighty male volunteers belonging to age $>18 \mathrm{yrs}$ to $<25 \mathrm{yrs}$ were included in the study after prior approval from the institutional academic research committee. Volunteers who were not willing to participate in the study and those having infection at the right axilla were excluded from the study. Volunteers will be positioned with the arm abducted at $90^{\circ}$, externally rotated and flexed at the elbow to expose the axilla and the neck turned contralateral. Only the right hand was used for the study. The axilla was scanned for the axillary artery, the conjoint tendon. The axilla was scanned close to the axillary artery using HFL-50 probe of X-Porte Ultrasound system (FUJIFILM Sono Site, Inc, Bothell, USA). This point is usually the site of classical description of ultrasound guided axillary brachial plexus block. This point was taken as A. We looked for the separation of musculocutaneous nerve at this point (Figure 1) and if present were noted. The separation of the nerve was taken as oval fish like nerve moving away from the plexus to enter the coracobrachialis (MCN exit point). If it was not seen, the probe was moved distally millimeter by millimeter to find out the site of separation. This was noted as point $\mathrm{B}$. The distance between A and $\mathrm{B}$ was noted. If already separated at point $A$, the ultrasound probe was moved proximally to identify the place of separation. This proximal point was noted as point $C$. The dis- tance between point $\mathrm{A}$ and $\mathrm{C}$ is also measured and noted. All measurements were subjected to simple descriptive analyses and results arrived at. With $15 \mathrm{~mm}$ possible distance from the plexus and power of 0.08 , allowable error of $5 \%$, a sample size of 76 was calculated. Hence a volunteer sample size of 80 was finalized.

\section{Results}

This prospective observational volunteer study was done after getting approval from the ethics committee of our institute. All the eighty volunteers were male. All of them completed the study and there were no drop outs in between. The scanning was only done in the right upper limb in all the cases. The mean age with its Standard Deviation (SD) was $20.2 \pm 1.19$ years (18-24). The mean and SD of the height of the patients was $162.7 \pm 5.24 \mathrm{~mm}$. The mean weight of the volunteers was $61.2 \pm 5.39 \mathrm{Kg}$. The mean and SD of the Body Mass Index (BMI) was $23.09 \pm 1.68$. In one out of eighty, the musculocutaneous nerve was not found. After thorough search of the other side also, it can't be identified. In the remaining 79 males, 5 had separation at point A i.e., at the site of classical injection point in ultrasound guided blocks (6.33\%). Twenty seven had the separation point proximally (34.17\%). Forty seven $(59.49 \%)$ volunteers had the separation of the nerve distal to point $\mathrm{A}$. The mean distances from point $\mathrm{A}$ to point $\mathrm{B}$ and point $\mathrm{A}$ to point $\mathrm{C}$ in the remaining 74 cases where the separation was not at the site of injection were noted. The average distance and SD between point $\mathrm{A}$

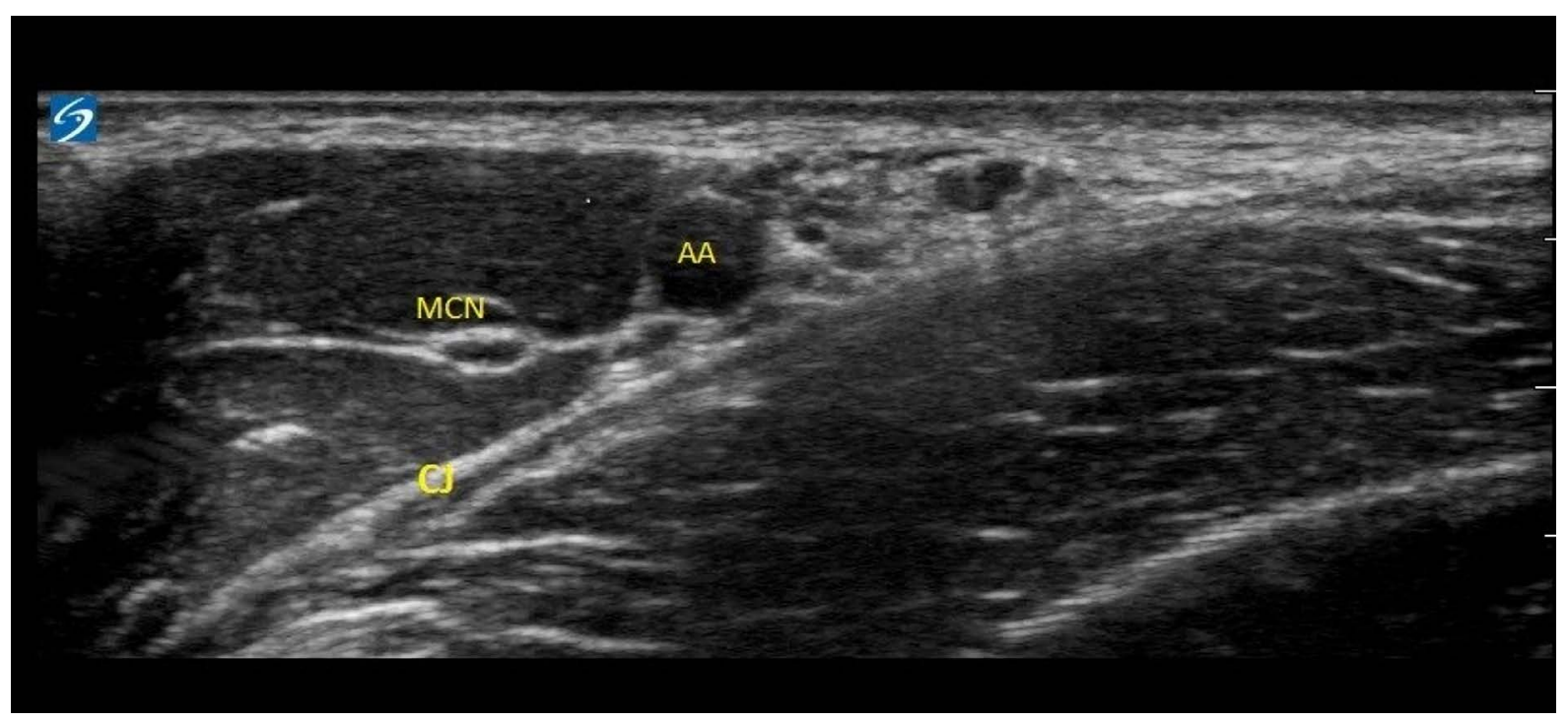

Figure 1. Showing axillary approach. AA - axillary artery, CJ - conjoint tendon MCN - musculocutaneous nerve. 
and point B i.e., distal was $21.17 \pm 8.46 \mathrm{~mm}$. The variable varied between 8 and $44 \mathrm{~mm}$. The mean distance between point $\mathrm{A}$ and point $\mathrm{C}$ (proximal) was $14.63 \pm 7.82 \mathrm{~mm}$. (6-35 mm). All the volunteers cooperated well and there were no untoward events.

\section{Discussion}

AXB is the one of the common approaches to brachial plexus due its simplicity and the distance from vital tissues like pleura and the site of needle prick. The most important problem encountered with this approach is the sparing of the musculocutaneous nerve ${ }^{4}$. Even though ultrasound improves the success rate of AXB blockage ${ }^{5}$, still the musculocutaneous nerve may separate at a different site to get spared during the procedure. Kjelstrup T et al., ${ }^{6}$ in their study of separation of musculocutaneous nerve did it by using MRI. The course of the MCN and position where it left the axillary sheath and perforated the coracobrachialis muscle (i.e., MCN exit point), with relation to the axillary artery and the block needle insertion point in the axillary fold, were recorded. They concluded that there was a difference of $36 \mathrm{~mm}$ from the point insertion site to the site of separation. In our study we found that the separation was proximal in $34 \%$ of volunteers while it was distal in 59\%. Such clear demarcation of separation is not studied in any of the earlier studies. There are a few anatomical studies ${ }^{7,8}$ which describes the various positions of origin of MCN and its significance in classification. The MCN is rarely absent and we had a case in one of our 80 volunteers. A thorough search of the other side also did not reveal a MCN. There are a few reports ${ }^{9,10}$ of congenital anatomical difference in which the MCN is absent. In our study, the mean distance and $\mathrm{SD}$ between point $\mathrm{A}$ and point $\mathrm{B}$ i.e. distal separation was $21.17 \pm 8.46 \mathrm{~mm}$. The variable varied between 8 and 44 $\mathrm{mm}$. The mean distance with SD between point A and point C (proximal separation) was $14.63 \pm 7.82 \mathrm{~mm}$. (6-35 $\mathrm{mm})$. This establishes the fact that the MCN can separate over a wide range of around $8 \mathrm{~cm}$. This is calculated from the maximal distance of both the points $\mathrm{B}$ and $\mathrm{C}$ $(35+44 \mathrm{~mm})$. If the distance is going to such a lengthy $8 \mathrm{~cm}$, it's not likely to get blocked in routine injections even its going to be multipoint procedure. Here we need to clearly demarcate that multipoint injection is different from multisite. In multisite, we take out the needle and insert in a different site either proximal or distal to target different nerves. Even with the use of nerve stimulator/ ultrasound, a single injection technique has been associated with less success rates ${ }^{11}$. A single study ${ }^{12}$ has found success with a minimal volume of around $2 \mathrm{ml}$ for AXB. In such low volume blocks it is quite impossible to travel $44 \mathrm{~mm}$ if the MCN has to be blocked in certain cases. The site of injection at point $\mathrm{A}$ is most likely to succeed in patients where the site of separation of MCN is at either point $\mathrm{A}$ or point $\mathrm{B}$. If the separation is proximal, then the block performed at point $\mathrm{A}$, where it is commonly administered is likely to spare the MCN. If the anatomy of MCN separation is in accordance with our findings, it's likely to happen in $34 \%$ of patients. The blockade of MCN is needed for the lateral part of the forearm and the avoidance of tourniquet pain. Maria et al. ${ }^{13}$ in their study has described the disadvantage of musculocutaneous sparing in evolution of tourniquet pain. Any distal separation may not be affected by deposition of the local anesthetic at the classically described site. In our study, we had $59 \%$ of cases with distal separation. Even though the MCN is visible separately after the distal movement of the probe, any proximal block is more likely to block the MCN. If the sheath is separate and the nerve is well inside the coracobrachialis muscle, the MCN sparing can take place even in cases of distal separation. We scanned the right upper limb in all the cases to avoid the bias of possible anatomical variations between sides. All our cases were routine healthy male volunteers of the age group of 18-24 to circumvent any possible anatomical variation $^{14,15}$. J.-L. Christophe et al., ${ }^{16}$ in their study of patients found the topography of each nerve in the axilla and found the anatomical variations are numerous but all nerves can be identified in a section in $78 \%$ of patients. There were doubts about identification also. But in our study, we concentrated on musculocutaneous nerve separation alone. Even multipoint injection of the drug may spare this nerve if the nerve has separated proximally. This sparing will definitely cause inadequate analgesia of the lateral part of the fore arm and pain on tourniquet which is a big anesthetic lacuna in the intraoperative period. Ours is a volunteer study while theirs is an interventional study. The distance of separation was more in our study which prompted us to propose that individual musculocutaneous nerve blockade is essential in administration of axillary approach to brachial plexus blocks. 


\section{Conclusion}

The musculocutaneous nerve separates from the brachial plexus sheath in $34 \%$ of volunteers proximal to the classical described site for USG guided axillary approach to brachial plexus block. This means that injection at the classical site may miss the nerve. The nerve separated distally in 59\% but a classical site injection may cover the MCN. With such a common variation in anatomy, identification of MCN and separately blocking the nerve assumes significance in anesthesia practice.

\section{References}

1. Ranganath A, Srinivasan KK, Iohom G. Ultrasound guided axillary brachial plexus block. Med Ultrason. 2014; 16(3):246-51. PMid:25110766

2. Raju PKBC, Coventry DM. Ultrasound-guided brachial plexus blocks. Continuing Education in Anaesthesia Critical Care and Pain. 2014; 14(4):185-91. Crossref

3. Kumar A, Sharma DK, Sibi E, Datta B, Gogoi B. Comparison of peripheral nerve stimulator versus ultrasonography guided axillary block using multiple injection technique. Indian J Anaesth. 2014; 58:700-4. Crossref PMid:25624532 PMCid:PMC4296353

4. Satapathy AR, Coventry DM. Axillary brachial plexus block. Anesthesiology Research and Practice. 2011; 1-5. Crossref PMid:21716725 PMCid:PMC3119420

5. Chan VW, Perlas A, McCartney CJ, Brull R, Xu D, Abbas S. Ultrasound guidance improves success rate of axillary brachial plexus block. Can J Anaesth. 2007; 54(3):176-82. Crossref PMid:17331928

6. Kjelstrup T, Sauter AR, Hol PK. The relationship of the musculocutaneous nerve to the brachial plexus evaluated by MRI. Journal of Clinical Monitoring and Computing. 2017; 31(1):111-5. Crossref PMid:26584952 PMCid:PMC5253152
7. Loukas M, Aqueelah H. Musculocutaneous and median nerve connections within, proximal and distal to the coracobrachialis muscle. Folia Morphol (Warsz). 2005; 64:101-8.

8. Uysal II, Karabulut AK, Büyükmumcu M, Unver Dogan N, Salbacak A. The course and variations of the branches of the musculocutaneous nerve in human fetuses. Clin Anat. 2009; 22:337-45. Crossref PMid:19090002

9. Bhanu PS, Sankar KD. Bilateral absence of musculocutaneous nerve with unusual branching pattern of lateral cord and median nerve of brachial plexus. Anatomy and Cell Biology. 2012; 45(3):207-10. Crossref PMid:23094210 PMCid:PMC3472148

10. Sud M. Absence of the musculocutaneous nerve and the innervation of coracobrachialis, biceps brachii and brachialis from the median nerve. J Anat Soc India. 2000; 49:176-7.

11. Handoll HH, Koscielniak-Nielsen ZJ. Single, double or multiple injection techniques for axillary brachial plexus block for hand, wrist or forearm surgery. Cochrane Database Syst Rev. 2006; 25:CD003842. Crossref

12. O'Donnell B, Iohom G. An estimation of the minimum effective anesthetic volume of $2 \%$ lidocaine in ultrasoundguided axillary brachial plexus block. Anesthesiology. 2009; 111:25-9. Crossref PMid:19512869

13. Maria PS, Aitziber E, Pilar P, Zuri-e L, Ane A, Rafael M. Tourniquet pain after ultrasound-guided axillary blockade. J Anest and Inten Care Med. 2017; 3(5):1-5.

14. Thakur KC, Jethani SL, Parsad V. Non piercing variation of musculocutaneous nerve. Journal of Evolution of Medical and Dental Sciences. 2015; 4(90):15515-7. Crossref

15. Aggarwal A, Puri N, Aggarwal AK, Harjeet K, Sahni D. Anatomical variation in formation of brachial plexus and its branching. Surg Radiol Anat. 2010; 32(9):891-4. Crossref PMid:20521147

16. Christophe J-L, Berthier F, Boillot A, Tatu L, Viennet A, Boichut N, Samain E. Assessment of topographic brachial plexus nerves variations at the axilla using ultrasonography. British Journal of Anaesthesia. 2009; 103(4):606-12. Crossref PMid:19700445 